\title{
ANAUÊ, ALVORADA E FLAMA VERDE: A IMPRENSA INTEGRALISTA E AS DISPUTAS PELO PODER POLÍTICO EM SANTA CATARINA
}

\author{
ANAUÊ, ALVORADA Y FLAMA VERDE: LA IMPRENTA INTEGRALISTA Y LAS \\ DISPUTAS POR EL PODER POLÍTICO EN SANTA CATARINA
}

\section{ANAUÊ, ALVORADA AND FLAMA VERDE: THE INTEGRALIST PRESS AND DISPUTES FOR POLITICAL POWER IN SANTA CATARINA}

\begin{abstract}
ANAUE, ALVORADA ET FLAMA VERDE : LA PRESSE INTÉGRALISTE ET LES CONFLITS POUR LE POUVOIR POLITIQUE DANS L'ÉTAT DE SANTA CATARINA
\end{abstract}

冲冲杀杀, 巴西法西斯的诞生和绿衣党:

三十年代巴西圣塔卡塔林娜州的法西斯印刷媒体和权力纷争

DOI: $10.5533 / 1984-2503-20135302$

João Henrique Zanelatto ${ }^{1}$

\section{RESUMO}

A Ação Integralista Brasileira criada em São Paulo em 1932 rapidamente expandiu-se para todo o Brasil. Em Santa Catarina começou a ser organizada em 1934; seu crescimento deu-se principalmente nas regiões com maior concentração de imigrantes alemães e italianos e seus descendentes. $O$ artigo busca demonstrar, através de uma breve análise da imprensa integralista, as disputas pelo poder político em Santa Catarina. Pretende-se demonstrar a vinculação desses órgãos com os partidos e grupos políticos, e como através dela se processava as disputas pelo poder político no estado. Ao analisar a imprensa integralista, pretende-se evidenciar as especificidades dos seus discursos e que essa não somente publicava textos nacionais, mas também participou ativamente das disputas pelo poder local.

Palavras-chave: Imprensa, Integralismo, Poder, Santa Catarina.

\footnotetext{
${ }^{1}$ Doutor em História pela Pontifícia Universidade Católica do Rio Grande do Sul. Mestre em História pela Universidade Federal de Santa Catarina. Professor Adjunto do Curso de História da Universidade do Extremo Sul Catarinense. Líder do Grupo de Pesquisa "História Econômica e Social de Santa Catarina" e Pesquisador do Núcleo de Estudos em Estado, Política e Direito. E-mail: jhz@unesc.net
} 


\section{RESUMEN}

La Acción Integralista Brasileña creada en São Paulo en 1932 rápidamente se ha expandido por todo Brasil. En Santa Catarina comenzó a ser organizada en 1934, su crecimiento se ha dado sobre todo en las regiones con mayor concentración de inmigrantes alemanes e italianos y sus descendientes. El artículo busca demostrar a través de una breve análisis de la imprenta integralista las disputas por el poder político en Santa Catarina. Se pretende demostrar la vinculación de estos órganos con los partidos y grupos políticos, y como a través de ella se procesaba las disputas por el poder político en el estado. Al analizar la imprenta integralista, se objetiva evidenciar las especificidades de sus discursos y que esta no solamente ha publicado textos nacionales, sino ha participado activamente de las disputas por el poder local.

Palabras clave: Imprenta, Integralismo, Poder, Santa Catarina.

\section{ABSTRACT}

"Ação Integralista Brasileira" [Brazilian Integralist Action] was created in São Paulo in 1932 and rapidly expanded throughout all of Brazil. Activities began in the state of Santa Catarina in 1934, and growth was mainly to be found in regions with a large concentration of German and Italian immigrants and their descendents. This article seeks to outline the disputes for political power in Santa Catarina, by means of a brief analysis of the integralist press. It aims to reveal these organs' links with political parties and groups, and how these facilitated the processing of disputes for political power in the state. In analysing the integralist press, the article aims to reveal the details of its discourse and how it did not just publish national texts, but also actively participated in the disputes for local power.

Key words: Press, Integralism, Power, Santa Catarina.

\section{RÉSUMÉ}

L'Action intégraliste brésilienne, constituée à São Paulo en 1932, s'est rapidement développée dans l'ensemble du Brésil. Dans l'État de Santa Catarina, le mouvement commença à s'organiser en 1934. Son expansion eut principalement lieu dans les régions où prédominaient les immigrants allemands et italiens, ainsi que leurs descendants. Cet article a pour objectif de mettre à jour, après une brève analyse de la presse intégraliste, les conflits en œuvre pour le pouvoir politique à Santa Catarina. Nous souhaitons montrer les liens entretenus par ces organes de presse avec divers partis et groupes politiques, et 
la façon dont ces liens ont catalysé les conflits pour le pouvoir politique dans cet État. Cette analyse de la presse intégraliste mettra en évidence les spécificités des discours y figurant. Nous verrons également que n'y étaient pas seulement publiés des textes à caractère national, les conflits pour le pouvoir local y occupant aussi une place significative.

Mots-clés: Presse, Intégralisme, Pouvoir, Santa Catarina.

\section{摘要}

巴西的法西斯主义的民族整合行动党(Ação

Integralista

Brasileira)

在1932年成立于圣保罗市，很快遍布整个巴西。

位于巴西南部的圣塔卡塔林娜州, 民族整合行动党成立于1934年并得到迅速发展, 主要原

因是这个州的主要人口是来自德国和意大利的移民及其后裔。本论文通过分析研究这个法西 斯主义组织的印刷媒体, 向读者展示了该州的权力纷争。作者揭示了这些法西斯主义媒体与 各种党派与政治组织的联系, 通过这种联系, 展示了圣塔卡塔林娜州的政治权力斗争。为了 研究法西斯的民族整合主义媒体，重点分析了它们的话语和政治参与一 它们公开发表的宣传文章和它们同时也积极参加的当地的权力斗争。

关键字：印刷媒体(Imprensa)，民族整合主义，权力，圣塔卡塔林娜州

\section{Introdução}

A ação Integralista Brasileira começou a ser organizada em Santa Catarina à partir de 1934. Seu crescimento ocorreu rapidamente, em especial nas zonas de colonização alemã e italiana, tornando-se uma das principais alternativas de oposição frente aos grupos políticos que estavam no poder do estado. $O$ crescimento do integralismo ocorreu dentro de um cenário de disputas e tramas ocorridas pelo espaço e pelo poder no pós-30 na política tanto no âmbito regional quanto no local ${ }^{2}$.

No estado havia o terceiro maior contingente de filiados ao integralismo, perdendo somente para São Paulo e Bahia. O crescimento integralista no estado materializou-se nas eleições municipais de 1936. Nesta eleição os integralistas lançaram quinze

\footnotetext{
${ }^{2}$ Este artigo constitui-se de uma parte do quarto capitulo de minha tese de doutorado defendida em 2007 na Pontifícia Universidade Católica do Rio Grande do Sul.
} 
candidaturas para prefeito e conseguiram eleger oito e mais 72 vereadores ${ }^{3}$. Elegeram prefeitos nas duas maiores cidades do estado: Joinville e Blumenau, cidades onde os republicanos e liberais uniram-se na tentativa de derrotar os integralistas ${ }^{4}$. Esses dados são relevantes para demonstrar a intensidade das disputas pelo poder político no estado. Essas disputas se processaram por meio de vários canais e a imprensa foi um deles.

\section{História Política e Imprensa: algumas considerações}

Este artigo alicerçou-se fundamentalmente na renovada história política e na imprensa. A abordagem da história política até alguns anos atrás enfrentava uma série de preconceitos. Isso ocorreu devido ao "descrédito em que foi lançado durante algum tempo o estudo dos fatos políticos pela afirmação de um interesse por outras dimensões da história", transformando a abordagem da história política no "próprio símbolo de uma história fora de moda". Isso porque até então a história política havia sido "admitida para ser essencialmente relacionada ao Estado; em outras palavras, era mais nacional e internacional, do que regiona ${ }^{\natural " . ~ E s s e ~ d e s c r e ́ d i t o ~ e m e r g i u ~ a ~ p a r t i r ~ d a s ~ c r i ́ t i c a s ~}$ contundentes que a história política recebeu do grupo dos Annales, provocando uma marginalização da dimensão política dos fatos sociais, pois a consideravam literária, passível de ser romanceada e, sobretudo, por fundamentar-se em conflitos localizados e de curta duração. "Cada vez mais essa história será conhecida como tradicional".

$\mathrm{Na}$ década de 1960, a crítica à história política viria do marxismo e do estruturalismo, contribuindo também para o descrédito da história política, ao identificá-la como um tipo de história que estava ancorada exclusivamente no acontecimento, na linearidade e na narração dos fatos.

O marxismo ao centrar a explicação histórica no primado da luta de classes e no econômico, marginalizou a importância do político que passou a ser analisado em

\footnotetext{
${ }^{3}$ Zanelatto, João Henrique (2007). Região, Etnicidade e Política: o Integralismo e as lutas pelo poder político no Sul Catarinense na década de 1930. Tese (Doutorado em História) - PUCRS, Porto Alegre.

${ }^{4}$ Gertz, René (1987). O Fascismo no Sul do Brasil, Porto Alegre: Mercado Aberto.

${ }^{5}$ Rémond, René (2003). "As eleições". In Rémond, René (Org.) (2003). Por uma história política, Rio de Janeiro: Ed. FGV, p. 44.

${ }^{6}$ Burke, Peter (1992). "Abertura a nova história, seu passado e seu futuro". In Burke, Peter (Org.) (1992). A Escrita da história: novas perspectivas, São Paulo: Editora da Universidade Estadual Paulista, p.10.

${ }^{7}$ Falcon, Francisco (1997). "História e poder". In Cardoso, Ciro Flamarion; Vainfas, Ronaldo (Orgs.) (1997). Domínios da historia: ensaios de teoria e metodologia, Rio de Janeiro: Campus, p. 68.
} 
decorrência do econômico ${ }^{8}$. Quanto ao estruturalismo, transformou "o político - visto como jurídico-político - de superestrutura em um nível, numa instância ou uma estrutura regional, visto ao lado de outras duas, a econômica e a ideológica9"; que, ao debateremse, o econômico, em última instancia, acaba sendo o determinante. Assim, historiadores das três correntes: Annnales, marxismo e estruturalismo foram responsáveis pelo descrédito sofrido pela história política até o final da década de 60 .

Na década de 1970, teve inicio um processo de revalorização e renovação da história política. Jacques Julliard foi um dos primeiros historiadores a propor a reversão do quadro da história política tradicional. Inicialmente apontou seus vícios e defeitos.

\begin{abstract}
A história política é psicológica e ignora condicionamentos, é elitista, biográfica mesmo, e ignora a sociedade global e as massas que a compõem; é qualitativa e ignora o serial; visa o particular e ignora a comparação; é narrativa e ignora a análise; é materialista e ignora o material; é ideológica e não tem disso consciência; é parcial e não sabe que o é; atém-se ao consciente e ignora o inconsciente; é pontual e ignora o longo prazo; numa palavra, porque esta palavra resume tudo na gíria dos historiadores, é factual. ${ }^{10}$
\end{abstract}

Depois de expor os defeitos e vícios, Julliard propôs a necessidade de renovação da história política, para que se recuperasse de seu atraso, e foi enfático ao considerar que "marxista ou não, o historiador não pode desinteressar-se do problema da natureza social do poder político"11". Até a década de 70, a história política era "a própria imagem e o exemplo perfeito da história dita factual ${ }^{12 "}$. Privilegiava o particular e o nacional, dando as costas para a possibilidade de comparações no espaço e no tempo.

A renovação que a história política vem experimentando nas últimas décadas pode ser entendida levando-se em consideração a amplitude das transformações sociais, e as "novas orientações da pesquisa histórica"1". Desse modo, nos últimos anos foram se multiplicando as manifestações de um retorno com força total da história política. $\mathrm{Na}$ década de 80 , a situação de descrédito foi sendo modificada, a renovação da história

\footnotetext{
${ }^{8}$ Felix, Loiva Otero (1999). "Historiografia política: impasses e rumos nas décadas de 1970-90". In Logos, Canoas, v. 11, n. 1 , p. 8.

9 Borges, Vavy Pacheco (1991/2). "História e Política: laços permanentes". In Revista Brasileira de História, São Paulo, v. 12, n. 23/24, p. 13.

10 Julliard, Jacques (1988). "A Política". In Le Goff, Jacques; Nors, Pierre (Orgs.) (1988). História: novas abordagens. 3. ed., Rio de Janeiro: Francisco Alves, p. 181.

${ }^{11}$ Ibidem, p. 280.

${ }^{12}$ Rémond, R. (2003). Op. Cit., p. 16.

${ }^{13}$ Ibidem, p. 19.
} 
política tomava fôlego "com o gradativo abandono da história política tradicional em favor de uma compreensão do político na história ${ }^{14 " . ~}$

A renovação da história política ainda pode ser observada também em diversos outros aspectos: os temas tradicionais, como os partidos, eleições, guerras ou biografias não foram abandonados, porém trabalhados em uma nova perspectiva, opinião pública, mídia ou discurso foram incorporados como novos objetos de análise; o contato com outras disciplinas como a sociologia, a antropologia, a lingüística, contribuíram para a produção de trabalhos sobre a sociabilidade, análise de discurso, ideologias, "mentalidades coletivas" e a cultura política. A renovação da história política passou pela interdisciplinaridade. Acrescenta-se a isso que a nova história política

Preenche todos os requisitos necessários para ser reabilitada. Ao se ocupar com o estudo da participação na vida política e dos processos eleitorais, integra todos os atores, mesmo os mais modestos, perdendo assim seu caráter elitista e individualista e elegendo as massas como seu objeto central ${ }^{15}$.

Esse processo de renovação e valorização da história política refletiu-se também em trabalhos de âmbito regional. Elas têm possibilitado fazer estudos comparados, encontrar peculiaridades singularidades dificilmente perceptíveis em uma história geral. Esses estudos têm se desenvolvido com a utilização da imprensa como evidencia primordial em especial o jornal. A análise dos jornais constitui-se em uma evidência importantíssima para a compreensão das disputas entre partidos e grupos que se digladiaram na luta pelo monopólio do poder político. Em Santa Catarina antes do golpe que deu inicio ao Estado Novo a imprensa foi significativa na disputas pelo poder político em âmbito regional e local. Os partidos políticos organizados no estado no pós-30 utilizaram-se sistematicamente da imprensa para difundir suas idéias e atacar os adversários.

Até a década de 1970 eram poucos os estudos que se valiam de jornais e revistas como fonte para a produção do conhecimento histórico. Por outro lado o que se observa é o reconhecimento da imprensa e dos impressos e não era nova a preocupação de se escrever a história da imprensa, "mas relutava-se em mobilizá-los para a escrita da

\footnotetext{
${ }^{14}$ Felix, L. O. (1999). Op. Cit., p. 58.

${ }^{15}$ Rémond, René (2003). Op. Cit., p. 7.
} 
história por meio da imprensa ${ }^{16}$." O que poderia explicar tal situação? A tradição do século XIX e as décadas iniciais do XX preocupada com a busca da verdade dos fatos que somente poderia ser atingido por documentos para qual os impressos estavam longe de ser relevantes. O historiador:

[...] deveria valer-se de fontes marcadas pela objetividade, neutralidade, fidedignidade, credibilidade, além de suficientemente distanciadas de seu próprio tempo. Estabeleceu-se uma hierarquia qualitativa dos documentos para qual o especialista deveria estar atento. Nesse contexto, os jornais pareciam pouco adequados para recuperação do passado, uma vez que essas "enciclopédias do cotidiano" continham registros fragmentários do presente, realizados sob o influxo de interesses, compromissos e paixões. Em vez permitirem captar o ocorrido, dele forneciam imagens parciais, distorcidas e subjetivas. ${ }^{17}$

Essa concepção foi criticada já na década de 1930 pela Escola de Annales, fato que não implicou em um reconhecimento da imprensa e de suas potencialidades. A centralidade da imprensa ocorreu com a renovação dos temas, problemáticas e os procedimentos metodológicos incorporados pela história. ${ }^{18}$

De modo geral, a imprensa reflete o mundo de seu tempo e ao mesmo tempo influencia na construção deste mundo e, portanto, possui história e historicidade ${ }^{19}$. 0 conteúdo produzido pela imprensa reflete os momentos políticos, econômicos e culturais de uma sociedade, numa época. Ao refletir o mundo de seu tempo, a imprensa não pode ser entendida como neutra, pois estabelece relações e conexões com sujeitos, instituições e ideologias, de modo que as publicações apresentadas aos leitores explicitavam um conjunto de interesses. Daí a importância na pesquisa com jornais "a análise do maior número deve ser a primeira garantia para o não cometimento de erro; ainda que não seja toda a garantia ${ }^{20 " .}$

A imprensa enquanto um instrumento político e social introduz práticas, maneiras de pensar, idéias dando significado às ações humanas e influenciando de forma decisiva na construção dos acontecimentos. A grande importância alcançada pela imprensa levou muitos autores a compará-la a um "quarto poder" nos países. No Brasil, a imprensa, ao

\footnotetext{
${ }^{16}$ Luca, Tânia Regina de (2005). "Fontes Impressas: História dos, nos e por meio dos periódicos”. In Pinsky, Carla Bassanezzi. (Org.) (2005). Fonte históricas, São Paulo: Contexto, p. 111.

${ }^{17}$ Ibidem, p. 112.

${ }^{18}$ Essa renovação da disciplina história pode ser encontrada nos estudos dos historiadores da terceira geração dos Annales, na renovação do marxismo em especial nos estudos dos historiadores ingleses, na renovação da história política dentre outras.

${ }_{19}$ Albert, P.; Terrou, F. (1990). História da imprensa. São Paulo: Martins Fontes.

${ }^{20}$ Elmir, Cláudio Pereira (1995). "As armadilhas do jornal: algumas considerações metodológicas de seu uso para a pesquisa". In Cadernos de Estudo do PPG em História da UFRGS, Porto Alegre, n. 13, p. 23.
} 
longo de suas diversas etapas, ao atuar na orientação, formação ou manipulação da opinião pública, "transformou-se em verdadeiro elemento constitutivo da sociedade e refletiu, através das páginas dos jornais, os diferentes momentos históricos do Estado Nacional Brasileiro, bem como influiu direta/indiretamente em cada um deles ${ }^{21 " .}$

Dessa maneira, a imprensa configurou-se em um instrumento imprescindível para as interpretações históricas, da formação sócio-político-econômico-cultural brasileira.

\begin{abstract}
A leitura dos discursos expressos nos jornais permite acompanhar o movimento das idéias que circulam na época. $A$ análise do ideário e da prática política dos representantes da imprensa revela a complexidade da luta social. Grupos se aproximam e se distanciam segundo as conveniências do momento; seus projetos se interpenetram, se mesclam e são matizados. Os conflitos desencadeados para a efetivação dos diferentes projetos se inserem numa luta mais ampla que perpassa a sociedade por inteiro. O confronto das falas, que exprimem idéias e práticas, permite ao pesquisador captar, com riqueza de detalhes, o significado da atuação de diferentes grupos que se orientam por interesses específicos. ${ }^{22}$
\end{abstract}

Como se pode observar a imprensa é uma evidência indispensável para as pesquisas que tem o político como seu objeto de estudo. Os trabalhos que utilizam o jornal como instrumento de análise podem ser arrolados sob duas vertentes básicas: uma história através da imprensa ou uma história da imprensa. No primeiro caso, o jornal serve de "fonte de informação para a reconstrução de um determinado elemento constitutivo de uma dada sociedade 23 ", e, no segundo, o historiador estuda o jornal "em si mesmo, sua evolução, suas manifestações e as formas pelas quais ele retrata os acontecimentos ${ }^{24, "}$ Neste escrito as duas vertentes de pesquisa acerca do jornal se cruzam e completam-se de tal maneira que a imprensa vem sendo utilizada tanto como fonte, quanto como objeto de análise.

Em Santa Catarina a Ação Integralista Brasileira fundou vários jornais, além daqueles que em alguns momentos deram apoio ao partido. Nesses jornais, foi difundida a doutrina integralista. O jornal configurou-se no principal instrumento por onde a doutrina chegava aos militantes. Os teóricos do Integralismo veiculavam suas idéias nos livros e os jornais eram encarregados de popularizar. Através do jornal, a doutrina integralista era materializada. "O jornal desempenhava, assim, a função de atualização e popularização

\footnotetext{
${ }^{21}$ Alves, Francisco das Neves (1998). O Discurso Político-Partidário Sul-Rio-Grandense sob o Prisma da Imprensa Rio-Grandina (1868-1895). Tese (Doutorado em História) - PUCRS, Porto Alegre, p. 9.

${ }_{22}$ Capelato, Maria Helena Rolim (1994). A imprensa na história do Brasil, São Paulo: Contexto/EDUSP, p. 34.

${ }^{23}$ Alves, F. das N. (1998). Op. Cit., p. 11

${ }^{24}$ Ibidem.
} 


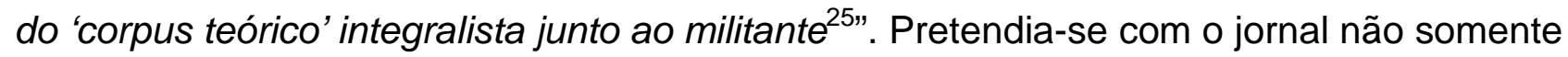
doutrinar, mas, sobretudo, "transmitir a doutrina de modo uniforme 26 ". Os jornais do interior do país "eram organizados de modo a reproduzir os jornais maiores, editados nos grandes centros onde se concentrava a elite dirigente do Movimento ${ }^{27 " . ~ A ~ i m p r e n s a ~}$ integralista de Santa Catarina não reproduziu somente os discursos dos jornais editados nos grandes centros, mas teve suas especificidades que serão abordadas a seguir.

\section{Anauê e o discurso nacionalista}

Anauê, foi o primeiro órgão integralista em Santa Catarina, foi dirigido por José C. Ramos e gerenciado por Chavier Schenk e Willian Benthien. Fundado em Joinville no ano de 1934, o jornal apresentava-se como um órgão que viria para combater incansavelmente até a vitória do movimento. Com um discurso extremamente nacionalista, os redatores pareciam estar se dirigindo em especial para os imigrantes alemães e seus descendentes, pois explicavam que por brasileiros entendiam "todos os que aqui vivem, sofrem e gozam conosco. Descendam de que raça descenderem. Queremos, exigimos, unicamente que se sintam, se considerem, se mostrem brasileiros $^{28, "}$.

Essa preocupação em alcançar os descendentes de alemães perpassou as publicações do Anauê, pois, além de possuir uma seção alemã, encontram-se também matérias enaltecendo a brasilidade dos teutos que estavam no Integralismo.

Nascidos no Brasil amam profundamente esta terra grandiosa, que se Ihes afigura um paraíso terreal. Vimol-os na lavoura, em pleno sertão, cultivando o solo; vimolos optimos soldados prestando serviços á Pátria; vimol-os, também nas letras, nas artes e na diplomacia, prestando inestimáveis serviços á nação. ${ }^{29}$

Anauê combatia também seus adversários políticos, denunciavam as violências cometidas contra os integralistas na região, e dessa maneira não se limitava a somente reproduzir notícias que eram publicadas nos grandes jornais do movimento. Dessa maneira, tanto Anauê quanto a Alvorada e Flama Verde, cada um em sua região, se

\footnotetext{
${ }^{25}$ Cavalari, Rosa Maria Feiteiro (1999). Integralismo: ideologia e organização de um partido de massa no Brasil (1932-1937), Bauru, SP: EDUSC, p. 79.

${ }^{26}$ Ibidem.

27 Ibidem.

${ }^{28}$ Anauê (1934), ano 1, n. 1, 14 de julho.

${ }^{29}$ Ibidem.
} 
envolveu nas disputas pelo monopólio do poder político, fato que se contrapõe à historiografia que argumentava que nos jornais do interior não se faziam "referências à política local, ou notícias locais que pudessem funcionar como fator de diferenciação ${ }^{30, "}$.

Um dado a ser destacado desses jornais era que os três eram dirigidos por lusobrasileiros e encontravam-se entre as pessoas de mais prestigio dentro do movimento. Isso fica evidenciado quando se observa a escolha dos candidatos a Câmara e ao Senado na convenção integralista. Cada região apresentou o seu candidato: "Othon D'Eça, pelo litoral; José Ferreira da Silva, pelo Vale do Itajaí; capitão Paulo Gonçalves Vieira da Rosa, pele Serra; Josino da Rocha Luores, pela zona do ex-contestado; José de Carvalho Ramos, pela zona do Norte e Antonio Dib Mussi pela zona do Sup1". Todos luso-brasileiros, nenhum descendente, nomes como Jaime Wendausen, (candidato a prefeito por Araranguá ${ }^{32}$ ) Aristides Largura, (prefeito de Joinville), e Alberto Stain, (prefeito de Blumenau) não figuraram entre os nomes escolhidos ${ }^{33}$. A alta hierarquia era também dirigida por lusos, demonstrando a força desse grupo étnico no movimento. Infere-se ainda, que tendo em vista a campanha da nacionalização, a direção integralista de Santa Catarina optou por candidatos luso-brasileiros para o senado e câmara federal preocupada com possíveis retaliações que poderiam vir a ocorrer contra candidatos teutos ou ítalos, caso fossem eleitos. Seguindo esta linha de raciocínio e observando que nas eleições municipais de 1936 os integralistas elegeram oito prefeitos e 72 vereadores, sendo a maioria deles constituída por descendestes de imigrantes alemães e italianos, pode-se dizer que havia uma preocupação da direção integralista catarinense em ter nomes luso-brasileiros buscando evitar desta maneira o crescimento do discurso nacionalista e a acusação de ser o integralismo um "nazismo disfarçado".

Destaca-se ainda outras tensões entre integralistas e oposição, que foram explicitadas pela imprensa. O deputado estadual Marcos Konder, líder da minoria, em um longo discurso proferido na Assembléia Legislativa, em agosto de 1935 tecia duras críticas aos comunistas e integralistas. Seu discurso foi posteriormente transformado em livro. Em resposta, o jornal Anauê, em novembro, publicava o artigo "O opúsculo do sr. Marcos Konder ${ }^{34, ", ~ n e l e ~ o ~ a r t i c u l i s t a ~ e m ~ u m ~ t o m ~ s a r c a ́ s t i c o ~ f o i ~ a n a l i s a n d o ~ o ~ l i v r o ~ d e ~}$

\footnotetext{
${ }^{30}$ Cavalari, R. M. F. (1999). Op. Cit., p. 79.

${ }^{31}$ Flama Verde (1937), ano I, n. 54, 25 de setembro.

${ }^{32}$ Araranguá era um dos maiores e importante município do Sul Catarinense na década de 1930.

${ }^{33}$ Aristides Largura e Albeto Stain governavam os dois municípios mais prósperos do estado. Ali estavam concentrados a maior parte da indústria e o comércio do estado.

${ }^{34}$ Anauê (1935), ano II, n. 16, 30 de novembro.
} 
Konder, citava pequenos trechos e procurava mostrar as contradições, explicava que o livro se apoiava na autoridade de Calógeras, tomando um terço do livro (chamava de livrinho).

Assim, por exemplo, o articulista citava um trecho do texto de Konder, no qual este dizia que o Integralismo era um travesti do fascismo italiano, inadequado às condições do Brasil, para, em seguida, responder: "o Integralismo é um movimento profundamente nacional, nada tendo que ver com o fascismo italiano que como bem disse Mussolini não é mercadoria de exportação ${ }^{35}$ ". E prosseguia, "se o Integralismo fosse inadaptável às nossas condições, como explicar o avanço estupendo deste movimento em todo o território brasileiro ${ }^{36 " . ~ S o m e n t e ~ c o n c o r d a v a ~ c o m ~ K o n d e r, ~ q u a n d o ~ a t a c a v a ~ o ~ c o m u n i s m o . ~}$

A partir de 1935, o Integralismo vai sofrendo ataque tanto dos republicanos quanto dos liberais. Em 1936, o governador Nereu Ramos, profundamente descontente com o resultado das eleições municipais, fazia uma declaração ao jornal Kolonie Zeitung, identificando o Integralismo ao nazismo, justificando a necessidade de uma política nacionalizadora.

Quero explicar-Ihes a vitória do integralismo, ou melhor, do hitlerismo. [...]. Eu disse hitlerismo, porque ali o fenômeno do integralismo não se apresenta com as mesmas características que nos demais estados da federação. Em todos os municípios em que o integralismo venceu predomina o elemento alemão. A bandeira não é Plínio Salgado, mas Hitler. Quando se pergunta a um colono 'és integralista', ele responde 'sou hitlerista'. É uma mística do militarismo alemão, como o caracterizou com muita propriedade o ministro. Marques dos Reis. [...]. Creio que está na hora de se iniciar uma enérgica obra nacionalizadora nos municípios em que a colonização alemã não quer adaptar-se à vida brasileira [...]. Isto significa: estacionar mais tropas nas zonas de imigração alemã, para que a mística do militarismo alemão tenha, em nossas casernas, um derivativo e os elementos teuto-brasileiros aprendam a integra-se na vida brasileira. ${ }^{37}$

O discurso do governador Nereu Ramos constitui-se de um feroz ataque as regiões onde os integralistas foram vitoriosos nas eleições municipais de 1936: o Vale do Itajaí e Norte do estado. Ao acusar o integralismo de ser um nazismo disfarçado e justificar a necessidade iniciar uma enérgica política naccionalizadora Nereu Ramos, representante

\footnotetext{
35 Ibidem.

${ }^{36}$ Ibidem.

${ }^{37}$ Gertz, René (1998). "Nazismo, fascismo, integralismo e o apoio das oligarquias no Rio Grande do Sul e Santa Catarina no Estado Novo". In Estudos Ibero Americanos, Porto Alegre, v. 14, n. 1, p. 27-28.
} 
das oligarquias tradicionais, estava também preocupado em controlar o avanço e "sustentar sua luta contra os grupos emergentes modernos das regiões de colonização". 38

No Sul Catarinense o jornal Sul do Estado, (do município de Laguna) órgão vinculado ao Partido Liberal publicava também várias reportagens desferindo ataque contra o Integralismo e suas lideranças. Com a nota intitula "O sr. Plínio Salgado está sofrendo grave enfermidade mental", o jornal publicava um texto do professor Fernando de Magalhães, do Rio de Janeiro, que afirmava a enfermidade do chefe integralista. "Estou desolado com a marcha da moléstia, pois aquelas alusões do sr. Plínio Salgado aos arcanjos e às espadas de fogo revelam alarmantes sintomas de paralisia geral”. Fica evidenciado na retórica do jornal uma nítida preocupação em desqualificar o líder integralista. Este discurso exagerado revela a preocupação com a popularidade e a aceitação do partido e de seu líder, isso tanto em âmbito nacional como local. Além dessa, as críticas ao Integralismo pautaram-se por publicações de textos procedentes de órgãos da imprensa nacional ${ }^{39}$. Ao analisar os jornais, observou-se que essas críticas ocorreram com maior intensidade tendo em vista a pressão exercida pelo vereador integralista Alberto Remor contra o legislativo e o executivo municipal ${ }^{40}$.

\section{Alvorada e o discurso da Brasilidade}

O jornal Alvorada, de Blumenau era de propriedade de José Ferreira da Silva, filiado a Ação Integralista Brasileira, eleito vereador em 1936, o mais votado. Foi dirigido, inicialmente por seu proprietário, e por um curto período dirigido por Aristides Largura, (Largura foi também professor em Blumenau e em 1936 já residindo em Joinville era eleito prefeito pelo Integralismo) posteriormente a direção era assumida por J. Schubert Jr. O semanário Alvorada, iniciou sua publicação a partir de 8 de janeiro de 1935. Em seu primeiro número, o jornal destacava no editorial que seu programa estava centrado no

\footnotetext{
${ }^{38}$ Ibidem, p. 28. Ver: Frotscher, Meri (2003). Da Celebração da Etnicidade Teuto-Brasileira à Afirmação da Brasilidade: Ações discursos das elites locais na esfera pública de Blumenau (1929-1950), Florianópolis: UFSC, p. 118. Conforme os autores em âmbito nacional a imprensa também atacou o Integralismo. $O$ jornal O Globo, na série de reportagens publicadas em 1937, sobre "a idéia do 'perigo alemão', que havia sido veiculada no Brasil durante a Primeira Guerra Mundial, toma também a forma de 'perigo nazista'. Além da idéia de um 'perigo nazista', na série de reportagens do jornal aparecem mais dois 'perigos' nas regiões de colonização alemã do Vale do Itajaí. Um deles referia-se a nacionalização escolar e o outro, ao movimento integralista".

${ }^{39}$ Sul do Estado (1937), 31 de julho.

${ }^{40}$ Flama Verde (1937), ano 1, n. 43, 3 de julho.
} 
lema: "Deus, Pátria, Família" e "que dentro desses princípios, não nos envolveremos jamais em questões político-partidárias ${ }^{41 " .}$

Contudo, na mesma página, o jornal estampava uma imagem de Hitler e um texto destacando o homem que há pouco mais de um ano havia implantado o nazismo na Alemanha, visto com desconfiança pelas nações liberais. Enfatizava ainda que a política externa da Alemanha estava "produzindo frutos que só os cegos se recusam a ver"4". A ênfase dada a Hitler e à Alemanha Nazista contradiz a proposta de não se envolver em questões político-patidárias. No entanto, a simpatia ao nazismo era algo que perpassava vários jornais da região naquele momento, e, portanto, não sendo um indicador para se afirmar que o jornal fosse se envolver com questões políticas.

Todavia, ao se analisar os artigos, notas e textos publicados pelo jornal, as questões político-partidarias locais serão uma constante. Uma grande preocupação do jornal foi tentar, através de seus artigos, resolver e atenuar as tensões entre os teutobrasileiros e os luso-brasileiros. Com o artigo intitulado "O colono europeu, sua aclimatabilidade e assimilação", o jornal destacava a importância e a contribuição do colono europeu para a colonização do Brasil. Apontava que a dificuldade enfrentada pelo imigrante europeu não foi de ordem física (a adaptação ao clima sub-tropical da região), mas sim de natureza social e política. No entanto, explicava que o luso-brasileiro, foi o primeiro colono a chegar ao Brasil, e que mais facilmente se adaptou e com "seu gênio aventureiro, aqui se fixou, fundando uma sociedade heterogênea na sua estrutura, mas verdadeiramente representativa dos valores nativos". Quanto aos colonos que vieram posteriormente, "encontraram no Brasil toda a série de antagonismos, bastantes poderosos para afrouxar o caracter mais animoso e enérgico de um povo". Mesmo diante da adversidade, o colono europeu "nem por isso abateu-se-Ihes a moral ou deformado foi seu caracter. A lucta travada foi renhida, mas a Victória lhes sorriu afinal". Por fim, o articulista do jornal finalizava o artigo exaltando os imigrantes alemães, italianos, poloneses e outros que estavam integrados à comunidade nacional, e "formam a base sólida sobre a qual há de assentar a verdadeira sociedade brasileira formada do amalgama dessas raças heróicas com o bravo lusitano e o guerreiro tupy ${ }^{43 " .}$.

Em outro artigo, intitulado "Integralismo e Brasilidade", o jornal procurava defender o Integralismo da acusação de ser um movimento desnacionalizador. Respondia que

\footnotetext{
${ }^{41}$ Alvorada (1935), ano 1, n. 1, 8 de janeiro.

${ }^{42}$ Ibidem.

${ }^{43}$ Alvorada (1935), ano 1, n. 28, 25 de julho.
} 
jamais havia surgido no país um movimento capaz de despertar o interesse das populações de origem estrangeira, pelas questões sociais, políticas e administrativas. As outras forças políticas despertavam o interesse da população somente nas campanhas eleitorais, "sem um sentido superior de brasilidade, porque giram em torno de um fato objetivo e limitado que se resume no nome do candidato e de duração efêmera porque desaparece uma vez depositada a cédula nas urnas ${ }^{44 "}$.

Diferenciando-se delas, o Integralismo mantinha suas sedes sempre abertas, em seus núcleos, em muitos deles havia escolas, onde as publicações doutrinárias e a propaganda "mantém ininterrupto e sempre vivo o interesse do povo pelas questões nacionais ${ }^{45 " . ~ E, ~ s o b r e ~ a ~ p o p u l a c ̧ a ̃ o ~ e s t r a n g e i r a ~ d i z i a ~ o ~ t e x t o: ~}$

E o nosso colono, o nosso artífice, o nosso comerciante ou industrial, o nosso homem de trabalho enfim, de origem estrangeira, que até aqui, fora das preocupações decorrentes de seu interesse individual e imediato, só tinha sua atenção voltada para os fatos que dizem respeito ao país de seus ancestrais, cujos jornais, cujos livros somente lia, hoje volta sua atenção para as cousas de sua Pátria. Si o faz através de sua língua materna, é porque a da sua Pátria não Iha ensinaram. ${ }^{46}$

Observa-se que o articulista do jornal se dirigiu a todos os setores da sociedade de Blumenau de origem estrangeira. Entre os patrocinadores do jornal figuravam pessoas dos vários setores. No jornal havia um número significativo de propaganda do comércio, de indústrias e de profissionais liberais. $O$ artigo finalizava explicando que essa população aos poucos estava se familiarizando com o novo ambiente "e por fim sentir-se-á brasileiro $^{47 " . ~ O ~ j o r n a l ~ f a z ~ u m ~ d i s c u r s o ~ v o l t a d o ~ p a r a ~ o s ~ i m i g r a n t e s ~ e u r o p e u s ~ e ~ s e u s ~}$ descendentes, pois foram essas populações os principais aderentes do integralismo no estado.

Dois outros artigos merecem destaque. Um deles, intitulado "Der Urwaldbote", e o outro publicado em março de 1937: "O Sr. Marcos Konder e o Integralismo". No primeiro, condenava o artigo publicado por Der Urwaldbote ${ }^{48}$ no qual atacava a população luso-

\footnotetext{
44 Alvorada (1935), ano 1, n. 32, 13 de agosto.

45 Ibidem.

46 Ibidem.

47 Ibidem.

${ }^{48}$ O Urwaldbote foi criado no município de Blumenau em 1893, pelo pastor Faulhaber, e até 1898 tratou especificamente dos interesses confessionais das comunidades protestantes. Em 1898, o pastor Faulhaber foi substituído por Eugen Fouquet, que dirigiu o jornal até 1927 (o Jornal foi vendido em 1900, para G. A. Koehler). Sob a direção de Fouquet e com novo proprietário, o Urwaldbote, além de defender o pangermanismo, se engajou nas querelas políticas do município, estabelecendo uma forte polêmica com os jornais brasileiros. Até 1917, foi um defensor das idéias do nacionalismo alemão, da Liga Pangermânica, e, na década de 20, lamentava a República de Weimar e esboçou opiniões anti-semitas. Com o afastamento
} 
basileira. Argumentava o articulista que como brasileiros, e como teuto-brasileiros, não poderiam deixar de condenar a emissão de "conceitos pouco lizongeiros aos lusobrasileiros, em artigo assinado pelo seu director e proprietário ${ }^{49,}$. Lamentava que o artigo do Der Urwaldbote ressaltava os defeitos dos lusos e as diferenças com os teutos, incitando ódio e malquerenças. Dizia ainda que a má vontade desse jornal para com os lusos já vinha de longa data. E num certo tom de ameaça, dava um recado dizendo "quem nasce em Blumenau, em Santa Catarina, no Brasil - é bom que 'Der Urwaldsbote' não se esqueça nunca - ou é brasileiro, ou é traidor, na feliz expressão de Lauro Muller ${ }^{50 " . ~}$ Finalizava conclamando, aos lusos e teutos, que, como brasileiros e como irmãos, deviam de mãos dadas e unidos construir a nação brasileira.

No segundo, Alvorada abordava a vinda de Marcos Konder (Os membros da família Konder exerceram muita influencia na política catarinense durante a Primeira República, assumiram a direção do Partido Republicano Catarinense em 1924 e chegaram ao governo estadual, com Adolpho Konder em 1926) a Blumenau no mês de março de 1937 para reorganizar o Partido Republicano. Konder, em uma das cartas endereçadas e publicadas pelo Der Urwaldbote atacava o Integralismo, dizendo que esse "andava a cortar, pela intensa brasilidade de sua doutrinação, os laços que antes prendiam o teuto-brasileiro à terra de seus paes ${ }^{51 "}$. Lamentava que em Blumenau e Jaraguá os teuto-brasileiros tivessem aderido ao nacionalismo integralista, que chamava de nativismos. Contrapondo-se a essas palavras, o articulista prosseguia "nessa campanha desnacionalizadora, o Sr. Marcos Konder está semeando o joio da discórdia, entre teutos e luso-brasileiros ${ }^{52, "}$

Marcos Konder, de volta a Blumenau, para reorganizar o Partido Republicano, depois da esmagadora derrota sofrida nas eleições de 36, usou a imprensa para atacar seu principal adversário naquele momento, fato que demonstra a importância dessa instituição na vida dos partidos. A imprensa permite aos partidos "introduzir aos poucos na

de Fouquet, em 1927, foi sucessivamente mudando de redatores, até 1941, quando deixou de circular. 0 Urwaldbote era um dos jornais de maior tiragem do Vale do Itajaí, nas eleições municipais de 1936 apoiou a União Democrática Blumenauense. Zanelatto, J. H. (2007). Op. Cit.

49 Alvorada (1935), ano 1, n. 58, 26 de novembro.

50 Ibidem.

${ }^{51}$ Alvorada (1935), 14 de novembro de 1935.

${ }^{52}$ Alvorada (1937), ano III, n. 167, 14 de março. 
opinião pública as idéias que defende e que, para determinada parcela da opinião, se tornam, se duradouras, verdades absolutas ${ }^{53 "}$.

Assim, a temática da brasilidade permeou os artigos publicados pelo jornal Alvorada. Isso pode ter ocorrido pelo fato de seu proprietário ser um luso-brasileiro, e que tinha pelo visto muita inserção junto à comunidade teuto-brasileira de Blumenau. José Ferreira da Silva, como já foi exposto, foi o vereador mais votado nas eleições de 36, e, além disso, exercia muita influência na gestão do prefeito Alberto Stein. O prefeito Alberto Stein foi eleito também nas eleições de 1936 pela Ação Integralista Brasileira.

Que outras questões eram tratadas por esse jornal? Para além das questões apontadas acima, os textos que constantemente eram abordados pela imprensa integralista: anticomunismo, liberalismo, destacar seus candidatos para as eleições municipais, fazer a campanha de Plínio Salgado para Presidência da República etc..., o jornal Alvorada contava com algumas seções: de esporte, militar (que apontava para os tipos de armas e munições e como usá-las), e a partir de 1936, com uma seção intitulada, "pelo mundo", trazia pequenos textos tratando de temas diversos de países, tanto europeus quanto latino-americanos. Divulgava as ações do prefeito municipal Alberto Stein, bem como os balaços mensais da administração.

\section{Flama Verde e a questão Sindical}

Quanto a Flama Verde, esse era dirigido pelo chefe provincial Othon D'Eça e gerenciado por Arnaldo Suarez Cuneo e Celso M. Caldeira. Nesse semanário, editado na Capital, entre 1936 e 1938, encontraram-se algumas características que a rigor o diferenciaram um pouco dos outros órgãos integralistas. Além das questões que eram comuns a todos os periódicos integralistas, na análise de Flama Verde pode-se perceber que esse procurava contemplar o Integralismo em âmbito estadual, pois as notícias veiculadas abrangiam as várias regiões do estado e seus municípios. Eram veiculadas notícias dos núcleos municipais e de suas atividades, a administração dos prefeitos e a atuação dos vereadores, a perseguição, prisão e morte de integralistas etc... Enquanto Flama Verde tinha uma atuação estadualizada, os demais órgãos da imprensa integralista restringiam-se ao município em que foram criados, no máximo divulgavam o Integralismo

\footnotetext{
${ }^{53}$ Berstein, Serge (2003). "Os partidos". In Rémond, René (2003). Por uma história política. 2. ed., Rio de Janeiro: Ed. FGV, p. 69.
} 
da sua região e, esporadicamente, traziam alguma notícia de outras regiões. Uma explicação para isso talvez seja o fato de o jornal estar na Capital, concorrendo com um número muito expressivo de outros jornais que publicavam notícias das várias regiões do estado.

Outra característica a ser destacada de Flama Verde é a questão sindical, essa perpassou praticamente todas as suas edições. Havia uma seção sindical, nela eram publicados artigos destacando a situação do sindicalismo e dos operários. Os comunistas eram combatidos, pois haviam dominado as posições de mando nos sindicatos. $\mathrm{O}$ artigo "Decadência do Sindicalismo" explicava que os sindicatos estavam "servindo aos interesses de Moscou, era preciso reformá-10 ${ }^{54 "}$. Em um outro artigo, "Manifesto dos trabalhadores integralistas aos syndicalistas do Brasil", abordava a realização da convenção trabalhista no Rio de Janeiro com a participação de trabalhadores de todo o país, evento no qual os integralistas catarinenses haviam participado com uma delegação. O manifesto apontava para a bandeira de luta pela unidade e autonomia sindical, contra 0 imperialismo financeiro, fiscalização e criação de leis trabalhistas, a decretação do salário mínimo, e campanhas visando o civismo e o patriotismo. "Queremos conclamar-vos para a grande campanha em favor do syndicalismo, em favor do prestigio e da efficiencia do syndicato, ameaçado ora pela demagogia communista, ora pela exploração da política ${ }^{55 " \text {. }}$

$\mathrm{Na}$ seção sindical, além dos artigos e notas sobre o sindicalismo, divulgava também a concepção integralista sobre o trabalho, o papel dos trabalhadores na sociedade, críticas à política trabalhista etc... A grande quantidade de artigos e notas publicadas por Flama Verde sobre os sindicatos e os trabalhadores sugere uma preocupação dos dirigentes desse jornal com o operariado. Mesmo sendo o discurso integralista voltado, sobretudo para a classe média ${ }^{56}$, ao que parece Flama Verde com sua retórica sindical estava buscando adeptos entre os trabalhadores ${ }^{57}$.

\footnotetext{
${ }^{54}$ Flama Verde (1936), ano I, n. 14, 12 de novembro.

${ }^{55}$ Flama Verde (1936), ano I, n. 16, 26 de novembro.

${ }^{56}$ Trindade, Hégio (1974). O fascismo brasileiro na década de 30, São Paulo: Difel; Porto Alegre: UFRGS. Chauí, Marilena; Franco, Maria S. Carvalho (1978). Ideologia e Mobilização popular, Rio de Janeiro: Paz e Terra.

${ }^{57}$ Dotta, Renato Alencar (2003). O Integralismo e os trabalhadores: as relações entre a AlB, os sindicatos e os trabalhadores através do jornal Ação (1936-1938). Dissertação (Mestrado em História) - FFLCH-USP, São Paulo.
} 


\section{Referências}

Albert, P.; Terrou, F. (1990). História da imprensa. São Paulo: Martins Fontes.

Alves, Francisco das Neves (1998). O Discurso Político-Partidário Sul-Rio-Grandense sob o Prisma da Imprensa Rio-Grandina (1868-1895). Tese (Doutorado em História) PUCRS, Porto Alegre.

Berstein, Serge (2003). "Os partidos". In Rémond, René (2003). Por uma história política. 2. ed., Rio de Janeiro: Ed. FGV, p. 57-98.

Borges, Vavy Pacheco (1991/2). "História e Política: laços permanentes". In Revista Brasileira de História, São Paulo, v. 12, n. 23/24, p. 7-18.

Burke, Peter (1992). "Abertura a nova história, seu passado e seu futuro". In Burke, Peter (Org.) (1992). A Escrita da história: novas perspectivas, São Paulo: Ed. Universidade Estadual Paulista, p. 7-37.

Capelato, Maria Helena Rolim (1994). A imprensa na história do Brasil, São Paulo: Contexto/EDUSP.

Cavalari, Rosa Maria Feiteiro (1999). Integralismo: ideologia e organização de um partido de massa no Brasil (1932-1937), Bauru, SP: EDUSC.

Chauí, Marilena; Franco, Maria S. Carvalho (1978). Ideologia e Mobilização popular, Rio de Janeiro: Paz e Terra.

Dotta, Renato Alencar (2003). O Integralismo e os trabalhadores: as relações entre a AIB, os sindicatos e os trabalhadores através do jornal Ação (1936-1938). Dissertação (Mestrado em História) - FFLCH-USP, São Paulo.

Elmir, Cláudio Pereira (1995). "As armadilhas do jornal: algumas considerações metodológicas de seu uso para a pesquisa". In Cadernos de Estudo do PPG em História da UFRGS, Porto Alegre, n. 13.

Falcon, Francisco (1997). "História e poder". In Cardoso, Ciro Flamarion; Vainfas, Ronaldo. (Orgs.) (1997). Domínios da historia: ensaios de teoria e metodologia, Rio de Janeiro: Campus, p. 61-89.

Felix, Loiva Otero (1999). "Historiografia política: impasses e rumos nas décadas de 197090". In Logos, Canoas, v. 11, n. 1.

Frotscher, Meri (2003). Da Celebração da Etnicidade Teuto-Brasileira à Afirmação da Brasilidade: Ações discursos das elites locais na esfera pública de Blumenau (19291950), Florianópolis: UFSC.

Gertz, René (1987). O Fascismo no Sul do Brasil, Porto Alegre: Mercado Aberto. 
(1998). "Nazismo, fascismo, integralismo e o apoio das oligarquias no Rio Grande do Sul e Santa Catarina no Estado Novo". In Estudos Ibero Americanos, Porto Alegre, v. 14 , n. 1, p. 21-29.

Julliard, Jacques (1988). "A Política". In Le Goff, Jacques; Nors, Pierre (Orgs.) (1988). História: novas abordagens. 3. ed., Rio de Janeiro: Francisco Alves, p. 180-196.

Luca, Tânia Regina de (2005). "Fontes Impressas: História dos, nos e por meio dos periódicos”. In Pinsky, Carla Bassanezzi (Org.) (2005). Fonte históricas, São Paulo: Contexto, p. 111-153.

Rémond, René (2003). "As eleições". In Rémond, René (Org.) (2003). Por uma história política, Rio de Janeiro: Ed. FGV, p. 37-55.

Trindade, Hégio (1974). O fascismo brasileiro na década de 30, São Paulo: Difel; Porto Alegre: UFRGS.

Zanelatto, João Henrique (2007). Região, Etnicidade e Política: o Integralismo e as lutas pelo poder político no Sul Catarinense na década de 1930. Tese (Doutorado em História) - PUCRS, Porto Alegre.

\section{Jornais}

Alvorada (1935), Blumenau, ano I, n. 1, 8 de janeiro.

Alvorada (1935), Blumenau, ano I, n. 28, 25 de julho.

Alvorada (1935), Blumenau, ano I, n. 32, 13 de agosto.

Alvorada (1935), Blumenau, ano I, 14 de novembro.

Alvorada (1935), Blumenau, ano I, n. 58, 26 de novembro.

Alvorada (1937), Blumenau, ano III, n. 167, 14 de março.

Anauê (1934), Joinville, ano I, n. 1, 14 de julho.

Anauê (1935), Joinville, ano II, n. 16, 30 de novembro.

Flama Verde (1936), Florianópolis, ano I, n. 14, 12 de novembro.

Flama Verde (1936), Florianópolis, ano I, n. 16, 26 de novembro.

Flama Verde (1937), Florianópolis, ano I, n. 43, 3 de julho. 
Flama Verde (1937), Florianópolis, ano I, n. 54, 25 de setembro

Sul do Estado (1937), Laguna, 31 de julho.

Recebido para publicação em novembro de 2012.

Aprovado para publicação em janeiro de 2013. 